\title{
A OPÇÃO TERCEIRO-MUNDISTA DE MÁRIO PEDROSA
}

\section{Carmen Palumbo MAC/USP}

\section{Resumo}

O capítulo chileno do exílio de Mário Pedrosa, terminado abruptamente em 1973 com o golpe ao governo Allende, e o subsequente exílio francês marcaram a passagem do crítico do europeísmo para a defesa de uma posição terceiro-mundista. Na França, Pedrosa escreveu o Discurso aos Tupiniquins e Nambás (1975), ponto de partida para uma reflexão sobre a América Latina que resultará, em 1978, em um verdadeiro projeto de descolonização do pensamento eurocêntrico a partir da arte ameríndia: a exposição (não realizada) Arte de viver, Arte de criar. Tendo como foco a década de 1970, último período de atuação política e intelectual do crítico, este trabalho tem como objetivo apresentar a opção terceiro-mundista de Pedrosa na vertente das teorias do "pensamento liminar", voltadas a reveindicar para o Brasil um lugar não mais de colônia, mas de locus de enunciação das narrativas historicamente subalternizadas.

\section{Palavras-chave:}

Terceiro-Mundismo; História da Arte; Mário Pedrosa.

A década de 1970 marca o despertar da consciência ecológica no mundo e alguns acontecimentos o demonstram: Conferência das Nações Unidas sobre Meio Ambiente em Estocolmo (1972), o surgimento do paradigma teórico da ecologia política, a proliferação de movimentos sociais ecologistas, a crise ecológica como crítica ao marxismo como modelo explicativo do funcionamento da sociedade. A suposta imensidão dos recursos naturais deixa lugar à mais-valia da natureza, que se descobre ser finita. Pela primeira vez, os problemas de degradação do meio ambiente provocados pelo crescimento econômico são percebidos como um problema global, que transcende a agenda política dos países em particular, e coloca em questão a soberania nacional de extensos territórios não devidamente protegidos.

Foi nesse clima que, no campo artístico, surgiram as críticas ao modelo desenvolvimentista e à

\section{Abstract}

The Chilean chapter of Mário Pedrosa's exile, finished abruptly in 1973 with the coup to the Allende government, and the subsequent French exile, marked the critic's crossing from Europeanism to the defense of a third-world position. In France, Pedrosa wrote the "Discurso aos Tupiniquins $e$ Nambás", starting point for a reflection on Latin America, that will result, in 1978, in a true project of decolonization of the Eurocentric thought from Amerindian art: the exhibition (not accomplished) "Arte de viver, Arte de criar". Focusing on the 1970s, the last period of political and intellectual activity of the critic, this paper aims to insert Pedrosa's third-world option in the liminary thinking theories, aimed at revealing to Brazil a place no longer a colony, but a "locus" of enunciation of historically subalternized narratives.

Keywords:

Third-Worldism; Art History; Mário Pedrosa.

manifestação de um certo antiamericanismo (ou antiestrangeirismo) ecológico de matriz latinoamericana. Se, em 1971, o artista argentino Uriburu propunha um continente latino-americano "unido pela Natureza" (PLANTE, 2012, p. 329), em 1976, Pedrosa postulava a existência de um quarto reino "mais pra lá dos três tradicionais da natureza, o animal, o vegetal, o mineral, quer dizer, o reino da arte", posicionado na linha abaixo do Equador (PEDROSA, 2013, p.105). Em uma relação mais justa do homem com a natureza (um relação orgânica, não prejudicada pelos avanços tecnológicos) estaria, segundo Pedrosa, o verdadeiro progresso humano, como demonstraria a arte coletiva, participativa e experencial dos povos ditos "primitivos".

Paralelamente ao surgimento de uma consciência ecológica coletiva, assiste-se, sobretudo a partir da segunda metade da década de 1970, o ingresso na 

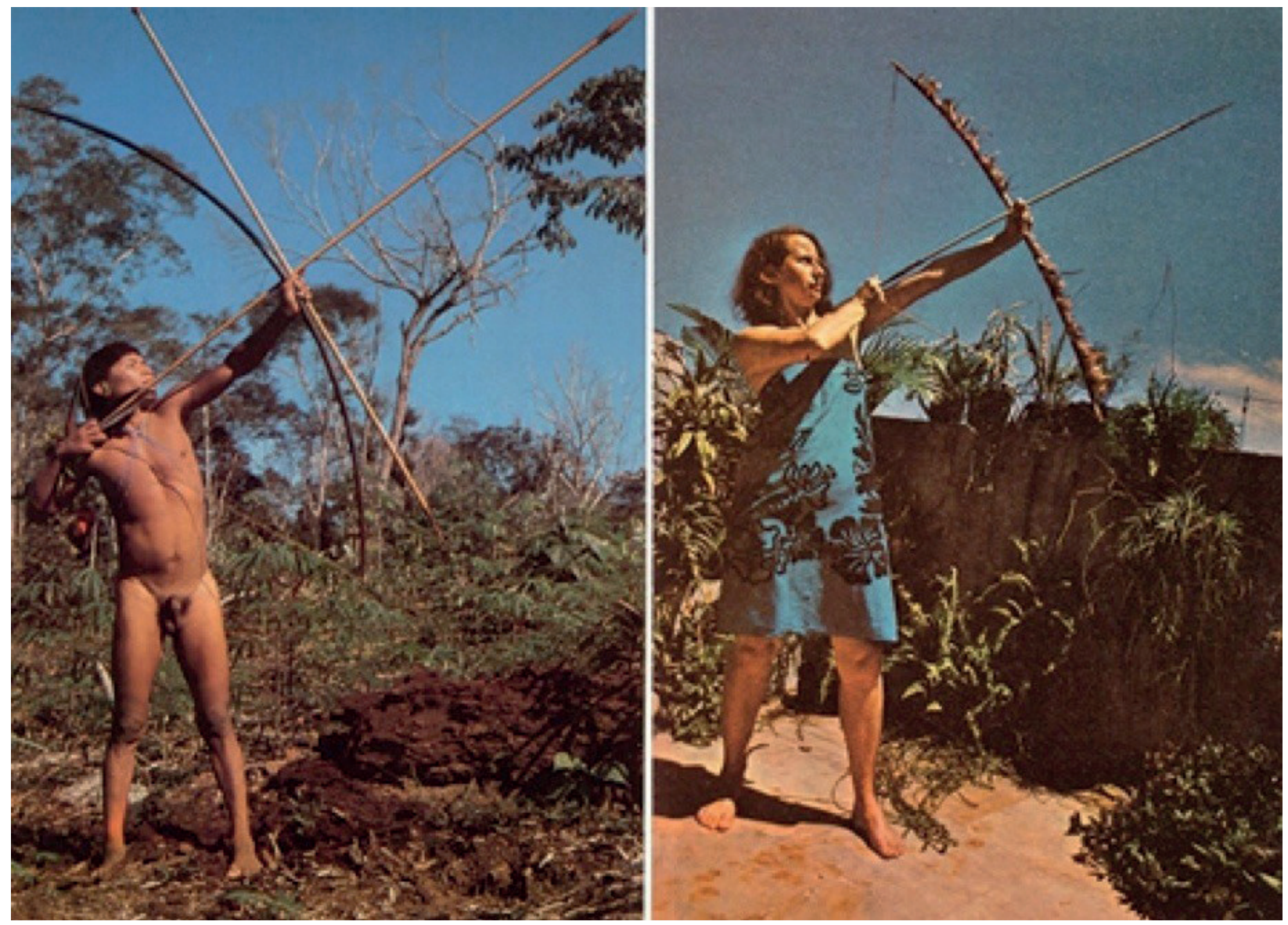

Figura 1 - Brasil Nativo / Brasil Alienígena, Anna Bella Geiger, 1977. Impressão digital com jato de tinta, $30 \times 20 \mathrm{~cm}$.

temática indígena no campo das artes visuais. Se, em 1978, a fotográfa Claudia Andujar organizava em São Paulo o grupo de estudos em defesa da criação de uma área indígena Yanomami ${ }^{1}$, um ano antes, Ana Bella Geiger tinha realizado a série Brasil Nativo / Brasil Alienígena, onde, em um jogo de contraposições entre a sua figura (de mulher/ intelectual/branca/urbana) e a figura do índio brasileiro, questionava a postura nostálgica da velha busca por uma identificação nacional e sua representação do brasileiro "nativo".

Frequentemente lida sob a perspectiva da irreversível degradação cultural e existencial das comunidades indígenas, a figura do índio brasileiro, condenado à perda da própria "cultura original", encontra-se, salvo raras exceções, historicizado, confinado ao início pré-cabralino da história de arte brasileira. Uma destas exceções é representada pela abordagem à produção indígena proposta por Mário Pedrosa nos textos críticos que, a partir dos anos 1960, expressaram o interesse de
Pedrosa pela temática terceiro-mundista, dentre eles, Discurso aos Tupiniquins e Nambás.

Escrito em 19752, depois da experiência chilena (1970-1973) ${ }^{3}$ e durante o exílio francês (19731977) ${ }^{4}$, o Discurso aos Tupiniquins e Nambás se insere no conjunto de textos escritos no período de afastamento forçado da pátria, período que coincidiu com a produção crítica direcionada a uma política cultural assentada na emergência da cultura popular e no esforço anônimo da criatividade para a coletividade (SOMMER, 2017, p. 118).

A década de 1970, que coincide com o último período da crítica e da militância política de Pedrosa, abre-se com o texto A Bienal de cá pra lá (1970) e se conclui com Variações sem temas ou a Arte da Retaguarda (1978), discurso da Conferência da Primeira Bienal Latino-Americana de 1978, o qual pode ser considerado como o último grande exercício de retrospectiva sobre o mundo da arte elaborado por Pedrosa, em que o crítico, no articular do percurso da arte moderna, foca na necessidade 
dos povos latino-americanos de se relacionar em uma grande unidade, a partir da "dimensão mestiça" comum a todos eles.

Discursos aos Tupiniquins e Nambás se insere no meio destes dois textos, vindo a representar a (ainda) não perdida esperança de uma nova arte latino-americana e a confiança no potencial revolucionário dos povos periféricos dos países "abaixo da linha do Equador, onde germina a vida e uma arte nova ameaça de brotar" (PEDROSA, 2013, p. 113). Tal otimismo aparecerá mais pálido, quase ausente, em Variações sem Tema, vindo a ser substituído, no início da década seguinte, pela dedicação total à causa política e à concretização do sonho socialista: o nascimento de um partido feito pelos trabalhadores.

Um ano antes de seu falecimento, o crítico deixava transparecer seu pessimismo em uma entrevista ao escritor Cícero Sandroni:

Estamos numa época de crise profunda, de crise ainda mais aguda no Terceiro Mundo. [...] Diante de conflitos tão radicais, terríveis, insolúveis, é natural que a arte passe para um nível secundário. A arte está em decadência e eu diria mesmo que está no fim, se é que ela pode acabar. Mas a arte não acaba. (PEDROSA apud SANDRONI, 1978).

Em 1978, Pedrosa ainda confiava na existência de sociedades propícias ao desenvolvimento do fenômeno artístico, enquanto outras já não o eram mais. No Discurso aos Tupiniquins e Nambás, o crítico propõe uma atenta análise geopolítica do "sistema-mundo" da arte na década de 70, apresentando as variáveis históricas, econômicas e políticas das idiossincrasias entre países do "primeiro mundo" e do "terceiro mundo".

Pedrosa discute sobre a anunciada morte da arte, evidenciando o estado de decadência dos centros de produção e distribuição da arte, localizados nas "sociedades desenvolvidas" em que a arte "perdeu sua autonomia existencial e naturalmente espiritual", reduzindo-se a mero capricho e objeto de luxo estetizante. "Já fora destas áreas - afirma Pedrosa - há as oficinas de artesanato, o trabalho não propriamente assalariado, mas onde se entrava o esforço anônimo da criatividade, da inventividade autêntica, quer dizer, o esforço para a coletividade." (PEDROSA, 2013, p. 105).
Ao falar de oficinas de artesanato e de anonimato à serviço da coletividade, Pedrosa referese às cooperativas de artesanato da União Popular do Chile de Allende, que o crítico teve a oportunidade de conhecer durante seu exílio chileno e que cita no texto Arte culta e arte popular, apresentado, em 1975, no Seminário de Arte Popular no México:

Com a organização das cooperativas artesanais,
o artesão torna-se livre dos comerciantes e
dessa forma ganha uma nova liberdade criadora,
desalienando o "gosto" ligado aos padrões sociais
dominadores (...) lentamente vão aparecendo nas
paredes da pequena burguesia (...) os tapetes
"crioulos" e a tecelagem de palha (...), vão
substituindo as más reproduções e as folhas de
calendário (...) contribuindo assim a formação de
um novo ambiente plástico íntimo para o chileno
(PEDROSA apud ARANTES, 1995, p.329).

Organização das cooperativas, desvinculação do artesão dos comerciantes e dasalienação do gosto burguês são os fatores que Pedrosa cita para descrever o processo de emancipação da arte popular chilena dos padrões da arte dita erudita durante o governo de Salvador Allende, no qual conforme relatado por Luis Corvalán: "o artesanato foi estimulado em todas suas expressões. Era outro ambiente. Dominava o desejo de estudar, de saber mais e de agradar o espírito com o prazer da arte e da cultura"5.

Como alternativa para a arte burguesa, Pedrosa aponta para o retorno do artista à condição de artesão, uma condição, porém, livre dos condicionamentos do mercado turístico, e que represente uma ruptura com a estrutura de classe e com o monopólio da burguesia sobre a produção artística.

Sendo os textos de 1975 a 1976 fortemente infuenciados pela experiência do exílio chileno, parece-nos que, para entendermos o terceiromundismo de Pedrosa, seja necessário contextualizar a atuação do crítico como gestor cultural no governo de Allende que, no breve período que teve à disposição, representou a concretização da utopia socialista, seja no plano econômico seja no cultural.

Pedrosa chegou em Santiago em outubro de 1970, convidado por Allende a trabalhar no Instituto de Arte Latinoamericano da Universidade do Chile e, logo depois, a criar o Museu de Arte Moderna 
e Experimental, primeiro nome do Museu da Solidariedade 6 , com obras doadas por artistas do mundo inteiro para o povo chileno. Durante seu exílio chileno, o crítico brasileiro teve a oportunidade de conhecer algumas políticas adotadas pelo governo Allende, revolucionárias em várias frentes. Em matéria de direitos indígenas, por exemplo, o governo socialista promoveu uma política, sem precedentes, de "reparação histórica" com a etnia Mapuche, orientada, principalmente, em duas direções:

- Reforma Agrária7, baseada na atribuição das terras usurpadas pelos latifundiários e na criação do Instituto de Desenvolvimento Indígena;

- Implementação de programas de educação ${ }^{8}$ focados na preservação da cultura indígena e no acesso ao sistema educacional nacional.

Com o reconhecimento da posse da terra e a introdução de medidas específicas para o reconhecimento da cultura mapuche, o governo de Allende realizava a "primeira oportunidade real que os mapuches tiveram para solucionar a difícil situação de marginalização política, social e territorial que vinham sofrendo desde a perda de sua independência"9.

Provavelmente inspirado pelas vivências do exílio chileno, Pedrosa começou a esboçar uma proposta política para a cultura que tivesse em consideração a realidade dos países "subdesenvolvidos", cuja problemática seria principalmente de ordem social:

Condenados a morrer nos próximos anos estão milhões de homem que passam fome, no Terceiro Mundo, assim como os nossos índios estão condenados a desaparecerem, condenados pela civilização do branco. (PEDROSA apud SANDRONI, 1978)

O depoimento aponta para duas preocupações que se tornaram sempre mais presentes no discurso de Pedrosa dos últimos anos de vida: a crise do capitalismo com suas consequências nas econômias dos países latino-americanos (a partir da perspectiva da teoria da dependência) e a questão indígena.

O Discurso aos Tupiniquins e Nambás aborda ambos estes aspectos, mostrando suas relações, por um lado, com o texto $A$ crise mundial do imperialismo e Rosa Luxemburg de
1976 (publicado no Brasil somente em 1979), e, por outro, com a "experiência amazônica" vivenciada durante o exílio chileno.

Quanto ao primeiro aspecto, durante o exílio francês, Pedrosa teve a oportunidade de analisar o quadro geral da crise do capitalismo sob a perspectiva da "dialética do capitalista e do não capitalista"10 de Rosa Luxemburg, e de enfrentar o tema da autogestão no campo socialista francês, oriundo das experiências de maio 68 . A teoria de Luxemburg, delineada no texto $A$ acumulação do capital (1913), focava na relação entre imperialismo, como método específico de acumulação do capital, e o capitalismo, do qual o imperialismo representava a última etapa. Segundo Luxemburg, numa sociedade capitalista, ou seja, dividida entre capitalistas e proletários, o esgotamento da demanda interna levaria o sistema capitalista a procurar fora de si os meios para sua existência, ou seja, nas economias periféricas do mundo por meio da conquista de colônias e de novos mercados.

Apesar das críticas que a teoria de Luxemburg recebeu por mais de uma geração de economistas, teve o mérito de pensar o sistema capitalista numa escala mundial e de refletir sobre a relação dialética entre centro e periferia, contribuindo, desta forma, para a formulação das teorias do subdesenvolvimento, que nos anos 1970, tiveram uma significativa circulação na América Latina. Abrindo o espaço para as relações de interdependência entre centro (países capitalistas) e periferia (países com economias naturais), os países periféricos não foram considerados apenas como fonte de acumulação de capital, mas como fator imprescindível do desenvolvimento capitalista mundial. Ou seja, para que haja desenvolvimento, é necessária a premissa do subdesenvolvimento.

Na linha de Luxemburg, Pedrosa reflete sobre a crise brasileira e a situação dos países desenvolvidos: "A civilização burguesa imperialista está num beco sem saída. Deste beco não temos que participar - os bugres das baixas latitudes e adjacências" (PEDROSA, 2013, pp. 108-109). Mas a proposta de Pedrosa é mais radical do que a da economista Luxemburg que, embora tenha contribuído de forma original à crítica da teoria marxista do capitalismo, não chegou a atribuir 
nenhum papel significativo, na luta anticapitalista, aos representantes das "economias naturais"11, os ditos "povos primitivos".

A opção terceiro-mundista se tornaria, em Pedrosa, projeto político, no qual a abolição do neocolonialismo implantado com a ditadura militar seria possível apenas com um projeto socialista democrático, em ruptura com o estado burguês, pois este "não admite [;] nenhuma transformação estrutural seja de que natureza for" (PEDROSA apud LOUREIRO, 2017). Nesse sentido, a teoria de Pedrosa exposta em Discurso aos Tupiniquins ou Nambás pode ser considerada um aperfeiçoamento da concepção marxista, na sua versão luxemburguista, por ter conferido um papel significativo ao potencial anticapitalista dos povos do Terceiro Mundo.

Quanto ao segundo aspecto, durante o exílio chileno, Pedrosa teve a oportunidade de conhecer a cultura indígena local, sua produção artística e de manter contato com o antropólogo brasileiro Darcy Ribeiro ${ }^{12}$ que, como ele, encontrava-se na condição de exíliado.

A ideia da exposição de arte indígena Alegria de viver, Alegria de criar, a ser realizada na volta do exílio, em julho de 1978 no MAM/RJ13, viria do "encantamento pela Amazônia" peruana, como o próprio Pedrosa revela em uma entrevista de junho de 1978, publicada na revista Arte Hoje:

A ideia de uma exposição de arte indígena foi consequência do meu exílio - interrompido pela vontade de voltar - quando ocorreu meu encantamento pela Amazônia. Foi súbito e intenso. Nasceu no Peru, onde me encontrava em visita à minha filha. (PEDROSA apud STREVA, 1978, p. 51).

Pedrosa não se aprofunda na descrição da experiência amazônica que o teria levado a imaginar a exposição sobre a temática indígena, mas, em outra passagem do Discurso aos Tupiniquins e Nambás, faz referência à arte primitiva, aquela que, contrariamente à arte dos países em estádio avançado de capitalismo, ainda mantém suas raízes na natureza. Nestes países pré-capitalistas a relação entre natureza e cultura não é dialética: "o que é natureza já é cultura e o que é cultura ainda é natureza" (PEDROSA, 2013, p.105).

Continuando na entrevista com Streva, o crítico apresenta as razões que fizeram recair a escolha do local de realização da exposição sobre o
Brasil: a não linearidade e não homogeneidade do processo desenvolvimentista brasileiro, declinado de forma diferente nas suas variadas aplicações regionais, e a ameaça existencial aos índios como resultado deste processo. A abordagem aos temas - cuja atualidade torna ainda mais lamentável a não realização da exposição de Pedrosa - prometida por ele é, na nossa opinião, o aspecto mais interessante do projeto curatorial da exposição Alegria de viver, Alegria de criar:

Quero mostrar que a comunidade indígena (;) é portadora de uma lição extraordinária para todos nós e sobretudo para a juventude brasileira, porque ela possui homogeneidade social e cultural, como em toda população dita primitiva, não capitalista, não desenvolvimentista, não progressista. Ela é a única que ainda vive de acordo com a natureza, que pode se isolar e manter certas características na sua constituição. (PEDROSA apud STREVA, 1978, p.51).

Pedrosa individualiza no índio o ponto de partida para despertar o país em crise, "que tende cada vez mais a ter uma arte sem profundidade e raízes, dependente, nas grandes cidades, de encomendas feitas pelo mercado de arte". Em outra passagem da entrevista, Pedrosa, em julho de 1978, afirmava:

O indígena é descompromissado com sistemas econômicos e políticos, é mais livre, e em tudo que faz - artefatos de trabalho como ralador de mandioca, cestas e zunidor, entre outras coisas - existe um senso danado, extraordinário, de proporção e finalidade, além de muito amor. Todos seus instrumentos de trabalho são belos em si e podem ser tomados como uma obra de arte, apesar do índio fazê-los com a natural segurança de quem está trabalhando para o fim coletivo da tribo e não somente para o seu prazer. Neste sentido, ele continua a velha tradição do artesanato, o artesanato pré-capitalista, que Marx achou ser a origem de toda a grande arte. (PEDROSA apud STREVA, 1978, p. 51).

Capital versus prazer. Prazer da criação enquanto fonte de alegria.

Alegria de viver, Alegria de criar iria mostrar a sociedade indígena em seu processo de trabalho, seu modo de viver para que o Brasil, em crise, retomasse um pouco as suas origens, para mostrar que esta arte, desligada de tudo, é feita por uma comunidade capaz de vencer o fascínio do capitalismo.

O aspecto inovador do projeto museológico da exposição planejada por Pedrosa é tal que seu valor supera a contingência do não acontecimento daquela que, se tivesse sido 
realizada, seria, muito provavelmente, lembrada como uma das exposições mais revolucionárias da história da arte contemporânea.

Na entrevista publicada na revista Arte Hoje, Pedrosa explica o projeto curatorial e expositivo da mostra que contava com a colaboração dos índios xinguanos, estruturando-se em três partes: a primeira dedicada à arqueologia, composta da lítica e cerâmica; a segunda concentrada no ambiente da floresta, com a apresentação da produção material indígena; a terceira dedicada aos rituais, às cerimônias, danças e músicas e à arte corporal ${ }^{14}$.

Com uma exposição que abrangeria desde a parte arqueológica até a produção contemporânea, a proposta de Pedrosa destinava-se, principalmente, "à juventude brasileira" que iria tomar conhecimento da homogeneidade social e cultural da dita população primitiva, definida pelo crítico "não capitalista, não desenvolvimentista, não progressista".

Neste ponto consite o aspecto mais revolucionário e anticolonial da abordagem historiográfica de Pedrosa à arte indígena: considerar a arte ameríndia não apenas como uma das raízes culturais brasileiras, mas como um elemento a partir do qual compreender a contemporaneidade.

Conforme analisado por Patricia Corrêa ${ }^{15}$, Pedrosa representaria no panorama brasileiro uma exceção, pela importância conferida à arte indígena como elemento para compreender os processos artísticos locais e vice-versa. Um interesse, aquele para a arte indígena, que coincide, no percurso crítico de Pedrosa, com a atenção dirigida, desde 1966, à arte pósmoderna que com a arte indígena compartilha seu caráter híbrido feito de materialidade e capacidade agentiva, sua dimensão coletiva e a plasticidade das estruturas perceptivas e situacionais. Conforme quanto afirmado por Pedrosa, o projeto expositivo da mostra:

Tomaria todos os três andares do MAM. Não seria só de pintura, ou de arte plumária, mas de um todo da vida cultural do índio (;) Entre as obras que eu queria colocar nesta exposição está um manto Tupinambá, obra muito importante, levada para Paris nos primeiros anos da colonização, no Século XVI. Nunca mais voltou. (PEDROSA et al., 1981, p.9).

Nesta perspectiva, a inclusão, no projeto expositivo, de um dos sete exemplares de mantos Tupinambá16

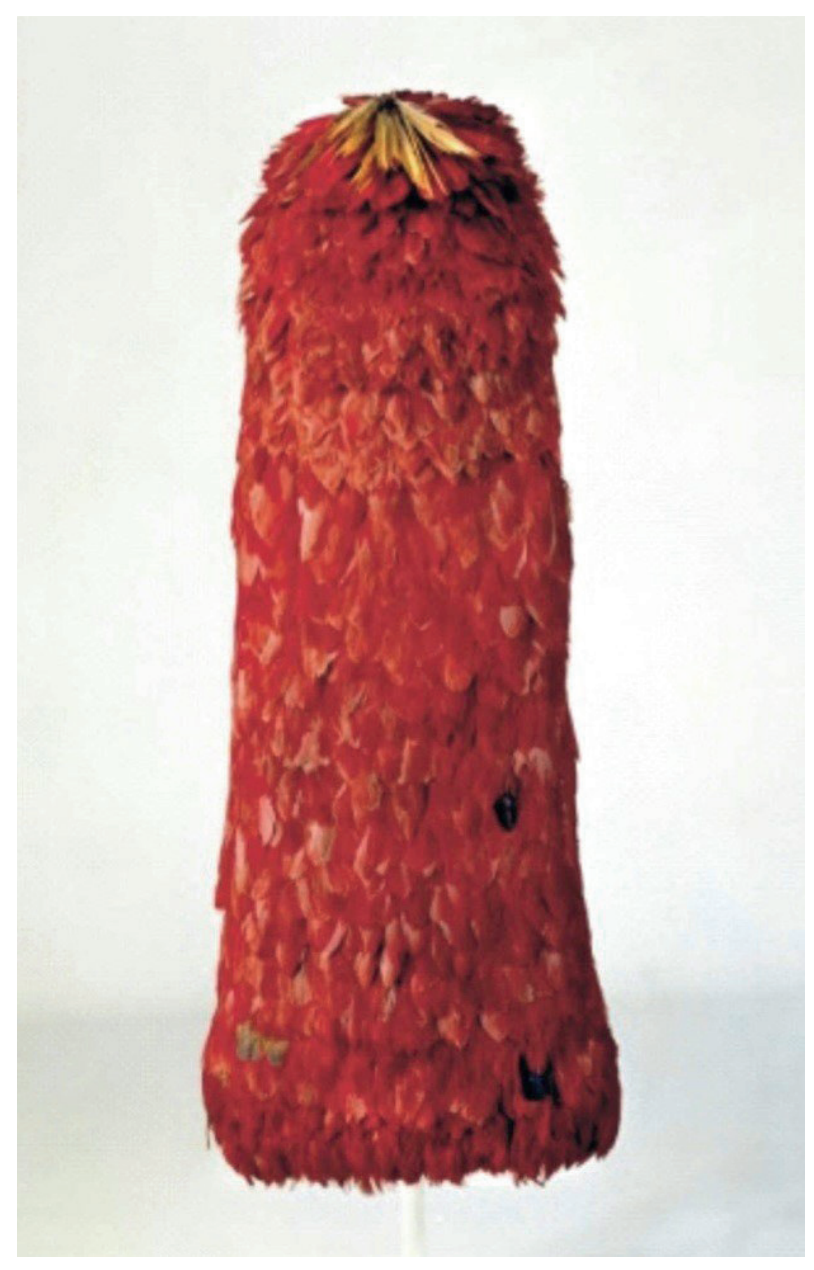

Figura 2 - Manto Tupinambá, etnia Tupinambá, séc. XVII, fibras naturais e penas de guará, Museu Nacional de Dinamarca (Nationalmuseet).

existentes no mundo, levado para o exterior pelo governador de Pernambuco, Maurício de Nassau, no século XVI, ultrapassava o valor museológico da peça, apontando para a dimensão criativa do índio, definido por Pedrosa o "Homem Criador" que plasma sua obra a partir da natureza.

E, além do manto Tupinambá, Pedrosa pretendia expor outras obras de arte indígena guardadas nos acervos de instituições museais localizadas na Suíça, Dinamarca e Alemanha, dentre elas algumas gravuras de cantos indígenas brasileiros feitos na década de 20. Complemetavam a parte expositiva filmes sobre a produção de mandioca, realizados com o intuito de mostrar o trabalho "da indústria indígena", gravações, a reconstrução de uma maloca; previa-se, também uma sala totalmente dedicada à música indígena, a realização de publicações e conferências organizadas de forma colaborativa com outras instituições, como o Museu Nacional, o Museu do 
Índio, o Museu Goeldi, o Museu Ipiranga, o Museu da USP e coleções particulares (STREVA, 1978, p. 52). Além disso, com o intuito de solucionar - problema de uma complicada e onerosa circulação da exposição em outras cidades e países, Pedrosa planejava a realização de um registro documental da exposição:

Pelo vulto da mostra e pela diversificação das
entidades colaboradoras, torna-se impossível o
deslocamento da exposição por outros estados e
possivelmente para outros países. O filme surge
como solução ideal para o deslocamento da
informação contida na mostra, além de ampliar
essa informação revelando e filmando os locais
de trabalho da equipe de arqueologia da cientista
Conceição Beltrão, que farão parte da exposição. A
entrada do homem na América do Sul é hoje estudo
que realiza Conceição Beltrão, estabelecendo
novas datações que recuam para quatro mil anos
a existência do homem no nosso continente. (...)
Pretendemos ir aos sítios de Rio Claro, em São
Paulo; Itaboraí, no estado do Rio, Paraíba, Piauí,
Xingu e Rio Uaupés. (SOMMER, 2017, p. 119).

A arqueóloga Conceição Beltrão era apenas um dos nomes de profissionais que compunham a lista de colaboradores de Pedrosa. Conforme informado por Sommer, a equipe do projeto contava com Lygia Pape, curadora adjunta; com os antropólogos Heloísa Fenelon, Eduardo Viveiros de Castro e Tereza Bauman; com os fotográfos Maureen Basilliat e Claudia Andujar; o programador visual Aloísio Carvão; o antropólogo Darcy Ribeiro ${ }^{17}$, em qualidade de consultor-geral, e com outros profissionais das áreas de arquitetura, técnica de montagem e luminotécnica (SOMMER, 2017, p. 119).

A exposição, "fundada sobre a necessidade de mostrar que Arte não é uma coisa artificial", abordava também a questão da relação do homem com a tecnologia, entendida por Pedrosa como uma ferramenta que "prepara, mas não cria nada nem ontem, nem hoje" (PEDROSA, 1981, p.9).

Significativo é o trecho seguinte, onde, interrogado por Ferreira Gullar sobre uma revisão do concretismo brasileiro a partir da arte indígena, Pedrosa afirma que, embora reconheça a importância do movimento no Brasil (sobretudo ligado ao surgimento da arquitetura moderna), suas ideias entorno da arte já eram outras:

Não acredito mais no que se chama de Arte Moderna, embora tenha tido uma importância colossal para o desenvolvimento cultural. Mas acabou, terminou sua função" (PEDROSA et al., 1981, p.9).
Para Pedrosa, o tempo das vanguardas tinha se esgotado e a Pop-Art era a demonstração mais visível deste processo.

Qual o lugar conferido por Pedrosa à produção indígena no cenário da arte brasileira do final da década de 1970 ? Como pensá-la na contemporaneidade? Ou melhor, como fugir do perigo de conferir ao interesse para a produção artística ameríndia um caráter nostálgico ou saudosista implícito no movimento de volta às origens?

A resposta, para Pedrosa, estava na contemporaneidade do ser índio, na sua capacidade de ser solução para a crise do "nosso mundo ocidental". Em uma "situação dramática", como a vivida pela sociedade brasileira, aflita pela fome, a prioridade é "defender uma raça brasileira que está condenada a desparecer (;) A saída é a revolução". E a revolução era exatamente o que Pedrosa queria fazer com Alegria de viver, Alegria de criar.

Portanto, podemos entender o projeto de Pedrosa como uma tentativa de descolonização do pensamento eurocêntrico a partir da perspectiva da cultura ameríndia, cuja "alegria de viver" (e de criar) se situa fora dos condicionamentos culturais que são de todos os outros seres, se não se conta com os ditos "loucos", outros "primitivos". Não por acaso, Pedrosa definiria a arte indígena e a "arte virgem" dois pilares fundantes para pensar as origens ${ }^{18}$, da cultura e do subconsciente, do Brasil. Pois, logo após o incêndio que destruiu o MAM/RJ e que inviabilizou o projeto da exposição sobre arte indígena, Pedrosa planejava a constituição do Museu das Origens, composto por cinco módulos, todos afins embora independentes entre si: o Museu do Índio, de Arte Virgem (Museu do Inconsciente), do Negro, de Arte Moderna e de Artes Populares.

Em um momento em que a questão indígena começava, muito timidamente, a ganhar espaço no debate político nacional e internacional, a opção terceiro-mundista de Pedrosa surgiu, no campo da crítica de arte e da curadoria, como uma proposta extremamente viva, inovadora, não menos revolucionária, também se confrontada com projetos mais recentes ${ }^{19}$.

O índio, raíz do povo brasileiro, era a "opção terceiro-mundista" de Pedrosa, um projeto 
político (ainda) por vir. Com o termo político não queremos atribuir ao discurso de Pedrosa o significado de um programa de partido ou de um manifesto partidário. Pois, é o mesmo Pedrosa que salienta a importância de distinguir a revolução política da revolução da sensibilidade:

A revolução política está a caminho, a revolução social se vai processando de qualquer modo. Nada poderá detê-las. Mas a revolução da sensibilidade, a revolução que irá alcançar o âmago do indivíduo, sua alma, não virá senão quando os homens tiveram novos olhos para olhar o mundo, novos sentidos para compreender suas tremendas transformações e intuição para superá-las. Esta será a grande revolução, a mais profunda e permanente, e não serão os políticos, mesmo os atualmente mais radicais, nem os burocratas do Estado que irão realizá-la. Confundir revolução política e revolução artística é, pois, um primarismo bem típico da mentalidade totalitária dominante. (PEDROSA, 1986, p. 247).

Atribuindo um significado político à opção terceiro-mundista de Pedrosa, queremos apontar para sua contemporaneidade, sua capacidade de mostrar a exigência, ainda vital, de uma nova perspectiva, de uma maneira de olhar o mundo com "novos olhos" para o despertar de "novos sentidos" que nos permitam compreender e superar as "tremendas transformações" ocorridas.

Acreditamos, também, no valor universal da opção terceiro-mundista de Pedrosa que, embora seja definida a partir de confins espaciais específicos (as terras dos Tupiniquins ou Nambás ou a linha abaixo do Equador), abrange o mundo, revelando seu potencial universal. Algo que Oswald de Andrade tinha muito bem resumido na "única lei do mundo", a antropofagia pré-capitalista, a-gramática, prélógica, que não precisa aprisionar a natureza em coleções botânicas. Uma antropofagia que é universal, simplesmente por não conhecer o que era "urbano, suburbano, fronteriço e continental". Nesta perspectiva, acredita-se que a opção terceiro-mundista de Pedrosa, assim como a filosofia oswaldiana, contribuiou para a definição da arte brasileira, a valoração e a formação de um sistema de pensamento independente, regido "segundo a lei do homem, a lei do antropófago". Um pensamento "liminar", segundo a definição de Walter Mignolo, em que as margens deixam de ser limites e començam a ser o "centro", o locus de enunciação de narrativas historicamente subalternizadas.

Talvez, poderíamos ver no pensamento de Pedrosa a antecipação de uma tendência que se tornará mais evidente a partir da década de 1990: o estabelecimento de um diálogo interdisciplinar entre áreas do conhecimento (história da arte, antropologia, arqueologia etc.), pois, a equipe de trabalho da exposição Alegria de viver, Alegria de criar contemplava profissionais de diferentes áreas. E não por acaso, entre os colaboradores de diferentes áreas, figurava o nome do antropólogo Eduardo Viveiros de Castro que, em 2009, elaborou o "pensamento da alma selvagem" em termos de questionamento à centralidade do pensamento cartesiano europeu em relação à linguagem mito-poética dos ditos "primitivos":

O "pensamento selvagem" não é o pensamento dos "selvagens" ou dos "primitivos" (em oposição ao "pensamento ocidental"), mas o pensamento em estado selvagem, isto é, o pensamento humano em seu livre exercício, um exercício ainda não domesticado em vista da obtenção de um rendimento." (CANTARINO; CUNHA, 2009 grifos dos autores)

Ou seja, a opção terceiro-mundista de Pedrosa vira, na linguagem de Eduardo Viveiros de Castro, "pensamento selvagem".

Neste silogismo, o "encantamento" de Pedrosa pela Amazônia transborda sua dimensão temporal e espacial, revelando o caráter extremamente contemporâneo e visionário do pensamento do crítico, segundo o qual o ponto de virada das vanguardas europeias estaria na área abaixo da linha do equador, lugar de resistência à "lei do aceleramento dos ismos" imposta pela sociedade de massa. Neste "outro" centro, a relação do homem com a natureza não responde às regras do tão invocado e almejado desenvolviment(ism)o e a produção artística é imbuída de um "senso danado, extraordinário, de proporção e finalidade, além de muito amor" (PEDROSA apud STEVA, 1978, p.51). Lugar de resistência onde "encantar-se" para encontrarse, a Amazônia torna-se, para Pedrosa, a solução à crise da sociedade contemporânea. Encontrase neste ponto o caráter inovador da proposta de Pedrosa, representado pela abordagem revolucionária à cultura e à produção material 
indígena, na medida em que torna a existência de outros mundos o ponto de partida para uma antropologia reflexiva.

\section{NOTAS}

01. O grupo criado por Andujar foi a versão embrional da ONG Comissão pela Criação do Parque Yanomami (CCPY), hoje denominada Comissão Pró-Yanomami que, em 1992, conseguiu efetivar a demarcação da terra indígena Yanomami.

02. Escrito em 1975, o texto foi publicado em 1976 no n4 da revista Versus.

03. Em 1969, Mário Pedrosa, então presidente da ABCA, manifestou-se publicamente contra a censura do governo militar e exerceu um papel importante na denúncia, à Anistia Internacional, dos casos de tortura praticados no Brasil. Em 1970, chamado a testemunhar em um processo aberto pelos militares para investigar a maneira de "denegrir a imagem do Brasil no exterior" de alguns intelectuais de esquerda, proclamou-se inocente, mas solidarizou com os torturados, passando de testemunha para indiciado. Avisado pelo seu advogado que seria decretada prisão preventiva, Pedrosa encontrou asilo político na embaixada do Chile, onde permaneceu até conseguir o documento que the permitiu viajar para aquele país, sob o governo de Salvador Allende.

04. Em 11 de setembro de 1973, um golpe militar derrubou o governo Allende. Pedrosa conseguiu abrigo na embaixada do México e, em seguida, viajou para Paris onde ficou quatro anos, até 1977, quando, revogado o mandado de prisão preventiva que havia contra ele, pôde voltar ao Brasil e, mais tarde, ser absolvido no processo ao qual respondia por "denegrir a imagem do Brasil no exterior".

05. CORVÁLAN, Luis. Elgobierno de Salvador Allende. Santiago: LOM Ediciones, 2003, p.31. Trecho original: "La artesanía fue apoyada y estimulada en todas sus expresiones. Había otro ambiente. Primaba el deseo de estudiar, de saber más y de darle al espíritu los disfrutes del arte y la cultura".

06. O Museu da Solidariedade chegou a realizar apenas duas exposições, uma em maio de 72 e outra em abril de 73, que apresentaram ao público as obras doadas ao acervo do Museus.

07. O então Ministro da Agricultura, Jacques Chonchol, restituiu aos Mapuches mais de 70 mil hectares de terra, criou 37 cooperativas de produção agrícola e numerosas cooperativas de artesãos cujo trabalho era reconhecido por um preço justo e pago pelo Instituto Nacional de Desenvolvimento Agropecuário (INDAP).

08. Em 1973, o governo chileno estabeleceu 17 mil bolsas para estudantes mapuches do quarto grau até o ensino universitário, promoveu cursos de alfabetização destinados a 27 mil alunos de ambos os sexos e se criou o Instituto de Desenvolvimento Indígena, que teria como missão formar centros educacionais de caráter politécnico para os filhos dos mapuches, promovendo o ensino da língua mãe, o mapudungún, nas escolas comunitárias, com o intuito de preservar as tradições culturais das comunidades indígenas.

09. CORVÁLAN, Luis. El gobierno de Salvador Allende. Santiago: LOM Ediciones, 2003, p.28. A declaração é da coordenadora Mapuche Arauco-Malleco que, em 1999, reconheceu as realizações feitas pelo governo popular de Allende. Trecho original: "El gobierno de Salvador Allende fue la primera oportunidad real que tuvieron los mapuches para solucionar la difícil situación de marginación política, social y territorial que les afectaba desde la pérdida de su independencia".

10. A definição é de Fernando Mires, em 0 discurso da Natureza: ecologia e política na América Latina, Florianópolis: Editora UFSC, Bernúncia Editora, 2012, p. 76.

11. Com o termo "economias naturais" Luxemburg designa as economias capitalistas do Terceiro Mundo, definidas também "o inimigo natural" do capitalismo.

12. Darcy Ribeiro (1922-1997) passou seu exílio nos países da América Latina (Uruguai, Venezuela, Chile e Peru), ocupando a posição de assessor do Presidente Allende no Chile e do Presidente Juan Velasco Alvarado no Peru. Neste período o antropólogo escreveu cinco dos seis livros da sua obra de maior repercussão: Estudos 
de Antropologia da Civilização. Ribeiro foi também o autor do capítulo sobre Arte Indígena inserido na obra coletiva História Geral da Arte no Brasil organizada por Walter Zanini (1983).

13. A exposição não foi realizada devido ao incêndio que, em julho de 1978, destruiu o MAM/RJ e quase a totalidade de seu acervo.

14. É interessante notar que na parte conclusiva de Discursos aos Tupiniquins e Nambás, Pedrosa faz uma uma valoração do estado no qual se encontra a body-art norte-americana e europeia na década de 1970, a partir da obra do austríaco Rudolf Schwarkogler que o crítico define "um gozo estético de primeira ordem". Pedrosa evoca a arte corporal ameríndia sem fazer alguma referência direta a ela, apenas deixando entender que, enquanto a arte corporal ocidental abortava a revolução artística prometida, tornando-se o "testemunho de um condicionamento cultural final, sem abertura, nem existencial nem transcendental" o berço da "arte nova" estava localizado abaixo da linha do equador (PEDROSA, 2013, p. 123).

15. Patricia Corrêa informa que, no período entre 1975 e 1983, três obras, consideradas até hoje referências fundamentais da historiografia artística brasileira, se preocuparam de inserir a arte indígena na narrativa de elaboração da visualidade nacional: História da Arte Brasileira (1975) de Pietro Maria Bardi, a obra coletiva Arte no Brasil (1979) coordenada por Pedro Manuel-Gismondi, História Geral da Arte no Brasil, outra obra coletiva, organizada por Walter Zanini. Embora com as devidas diferenças entre si, as três obras colocaram a arte indígena no começo da timeline da História da arte brasileira, enquanto Pedrosa, em sua análise, exaltou a atualidade da arte indígena entendida como chave de leitura da arte brasileira contemporânea (CORRÊA, 2016, p.324).

16. Até hoje a peça integra o acervo do Nationalmuseet, de Copenhague, na Dinamarca e só saiu de lá uma vez, para ser exposto na Mostra do Redescobrimento: Brasil+500, curada por Nelson Aguillar e inspirada na ideia de Museu das Origens de Pedrosa. Por ocasião desta exposição, o manto foi reivindicado pela etnia Tupinambá de Olivença, na Bahia. Desde então, porém, apesar de contarem com o apoio de universidades e outras organizações, não tiveram sucesso em reaver os objetos.
17. Darcy Ribeiro é o autor do capítulo dedicado à Arte Índia do livro História Geral da Arte no Brasil, organizado por Walter Zanini publicado, em dois volumes, em 1983 pela Editor Instituto Walther Moreira. No mesmo ano, Zanini, na qualidade de curador da XVII Bienal de São Paulo realizou, com a curadoria de Noberto Nicola, a exposição Arte Plumária no Brasil, desdobramento da homônima exposição realizada em 1980 no MAM/SP por Nicola.

18. O Museu das Origens não foi realizado devido também à resistência ao projeto do então presidente do MAM/RJ, o cirugião plástico Ivo Pitanguy.

19. Em 2015 Eduardo Viveiros de Castro realizou, no Sesc Ipiranga, em São Paulo, a exposição Variações do corpo selvagem na qual apresentou as fotos realizadas durante o trabalho de campo realizado com os índios Araweté, Yanomami, Yawalapiti e Kulina, entre meados dos anos 1970 e início dos 1990.

\section{REFERÊNCIAS BIBLIOGRÁFICAS}

AMARAL, Aracy .(Org). Mário Pedrosa, Dos Murais de Portinari aos Espaços de Brasília. São Paulo: Editora Perspectiva, 1981.

ANDRADE, Oswald de. Manifesto antropófago. Revista de Antropofagia, São Paulo, no.1, maio de 1928, pp. 3 - 7 (ICAA RECORD ID 771303).

CANTARINO, Carolina; CUNHA Rodrigo. Eduardo Viveiros de Castro. Entrevista. Revista Com Ciência, São Paulo, de 10 de maio de 2009. Disponível em: http:// www.comciencia.br/comciencia/handler. php? section $=8 \&$ tipo $=$ entrevista\&edicao $=46$

CORRÊA, Patricia. Arte indígena e arte brasileira: justaposições críticas com Mário Pedrosa. Revista do Programa de Pós-Graduação em Arte da UnB, Brasília, Vol. 15, n²/julho-dezembro, 2016, pp. 319-338.

CORVALÁN, Luis Lépez. El gobierno de Salvador Allende. Santiago: LOM Ediciones, 2003.

FILHO, César Oiticica (Org.). Mário Pedrosa: Encontros. Rio de Janeiro: Beco do Azougue, 2013. 
MIGNOLO, Walter. Espacios geográficos y localizaciones epistemológicas o la ratio entre la localización geográfica y la subalternización de conocimientos. In: Revista de Investigaciones Literarias y Culturales. Caracas, v.6, n.11, jan, 1998.

MIRES, Fernando. 0 discurso da Natureza: ecologia e política na América Latina. Florianópolis: Editora UFSC, Bernúncia Editora, 2012.

PEDROSA, Mário. A arte não é fundamental. A profissão do intelectual é ser revolucionário. Entrevista concedida a Félix de Athayde, Washington Novaes, Lygia Pape, Hélio Pellegrino, Ziraldo et al. Pasquim, ano XIII, $\mathrm{n}^{0}$ 646, 12/18 novembro, 1981. pp. 7-11.

, Mário. Arte culta e arte popular. In: ARANTES, Otília (Org.). Política das Artes. São Paulo: Edusp, 1995, pp. 321-332.

Mário. Mundo, homem, arte em crise. São Paulo: Editora Perspectiva, 1986.

PLANTE, Isabel. Argentinos de París. Arte y viajes culturales durante los años sesenta. Buenos Aires: Edhasa, 2013.

SANDRONI, Cicero. A arte está em decadência, mas os sindicatos estão vivos. Jornal do Brasil, 2 de junho de1978.

SOMMER, Michelle. Nós, os bugres das baixas altitudes e adjacências. Desterros, terreiros: pós cadernos 2 / PPGAV UFRJ. Rio de Janeiro: Escola de Belas Artes, Editora Circuito (co-ed.), 2017, pp. 103-128.

STREVA, Sônia. As vanguardas já nasceram cansadas. Arte Hoje 1, n012, junho, 1978, pp. 51-53.

\section{SOBRE A AUTORA}

Carmen Palumbo possui graduação em Comunicação pela Universidade de Bolonha (Itália); é aluna de mestrado do Programa de Pós-Graduação em Estética e História da Arte (PGEHA) do Museu de Arte Contemporânea da Universidade de São Paulo (MAC/USP) e membro do Grupo de Estudos em Arte Conceitual e Conceitualismos no Museu (GEACC) da mesma instituição. 